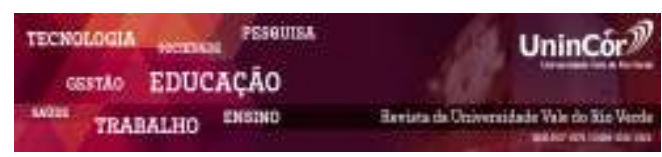
Revista da Universidade Vale do Rio Verde
ISSN: 1517-0276 / EISSN: 2236-5362

Vol. 16 | n. 1 | Ano 2018

Carlos Roberto Rodrigues Universidade Vale do Rio Verde carlos.rr@bol.com.br

Luiza Procópio Sarrapio Universidade Vale do Rio Verde luiza.sarrapio@unincor.edu.br

\section{AS CONTRIBUIÇÕES DO XADREZ PARA O PROCESSO DE ENSINO- APRENDIZAGEM: ASPECTOS SOCIAIS E PEDAGÓGICOS DO JOGO NA ESCOLA}

\title{
RESUMO
}

Objetivou-se, no presente artigo, por meio de pesquisa bibliográfica, versar sobre as contribuições do xadrez para o processo de ensino-aprendizagem, mostrando-o como agente facilitador e motivador dos aspectos sociais e pedagógicos na escola. A escolha da temática de pesquisa se justificou, pois, o xadrez quando introduzido na sala de aula, como parte diversificada do currículo, se faz proposta de melhoria gradativa de habilidades de raciocínio e educação disciplinar e pluridisciplinar, haja vista a infinidade de oportunidades de ser integrado a demais disciplinas. Concluiu-se que o xadrez é sinônimo de estímulo e motivação para o desenvolvimento da inteligência dos alunos, bem como para o reforço de regras e de disciplina entre eles, modificar a cultura na escola, desenvolve habilidades e garante conhecimentos a serem adquiridos no contexto escolar.

Palavras-Chave: Xadrez. Motivação. Ensino-Aprendizagem.

\section{THE CONTRIBUTIONS OF CHESS TO THE TEACHING-LEARNING PROCESS: SOCIAL AND PEDAGOGICAL ASPECTS OF THE GAME AT SCHOOL}

\begin{abstract}
The objective of this article was to present a bibliographical research about the contributions of chess to the teaching-learning process, showing it as a facilitating and motivating agent of social and pedagogical aspects in the school. The choice of the research theme was justified because, when introduced in the classroom as a diversified part of the curriculum, chess is proposed as a gradual improvement of reasoning skills and disciplinary and pluridisciplinary education, given the infinity of opportunities to be Integrated to other disciplines. It was concluded that chess is synonymous with stimulation and motivation for the development of student intelligence, as well as for reinforcement of rules and discipline among them, modify the culture in the school, develop skills and guarantee knowledge to be acquired in the school context.
\end{abstract}

Keywords: Xadrez. Motivação. Ensino-Aprendizagem. 


\section{INTRODUÇÃO}

Para educadores e pesquisadores da educação, os jogos utilizados na escola trazem benefícios aos sujeitos envolvidos, pois proporcionam além de diversão, a apropriação do conhecimento. Deste modo, os jogos são reconhecidos como ferramenta didática, fonte e motivação para a aprendizagem e para o aprimoramento de habilidades.

O xadrez é considerado por muitos estudiosos como um jogo clássico e sua verdadeira origem ainda é um grande mistério; é associado por seus especialistas com o desenvolvimento da inteligência humana. Em seus primórdios, definiu-se como exercício mental e, a partir de então, uma infinidade de estudos foram desenvolvidos na tentativa de provar que pode ser facilitador do desenvolvimento da inteligência humana.

No contexto escolar e dentro das salas de aulas, é frequente a reclamação por parte dos educadores sobre o déficit de concentração dos alunos, sobre a dispersão (trocar a palavra) em momentos de trocas de informações, bem como de indisciplina e desrespeito às regras. Assim, por ser um jogo, questiona-se: o xadrez pode contribuir para integração de eixos no currículo da educação básica?

São três hipóteses norteadoras de pesquisa: (1) acredita-se que, se o xadrez for ensinado didaticamente na sala de aula, pode ser sinônimo de estímulo e motivação para o desenvolvimento da inteligência dos alunos, bem como para o re- forço de regras e de disciplina entre eles; (2) acredita-se que o xadrez possa modificar a cultura na escola, pois é capaz de desenvolver habilidades e garantir conhecimentos não só no que tange ao aspecto lúdico, mas por ser capaz de promover a disciplina, e estabelecer vínculos sociais. Além disso, ele pode ser ferramenta lúdica para promoção da concentração e; (3) supõe-se que, por ser o xadrez uma forma lúdica de concentração, sua prática na escola possa auxiliar no desenvolvimento disciplinar dos alunos, haja vista que o exercício intelectual promovido pelo jogo é necessário ao treino da agilidade do raciocínio, da memória e das competências individuais; além disso, é fator motivador de criação, de aceitação e de cumprimento de regras necessárias para a solução de problemas no cotidiano da sala de aula e do contexto escolar.

O objetivo geral do presente artigo é versar sobre as contribuições do xadrez para o processo de ensino-aprendizagem. Já o específico é mostrá-lo como agente facilitador e motivador dos aspectos sociais e pedagógicos na escola.

Qualquer jogo, no espaço escolar, é capaz de envolver leitura, regras, métodos e fundamentos capazes de orientar as relações existentes entre os jogadores e o jogo - sem seguir as regras, nenhum jogo pode ser levado adiante por quaisquer jogadores. Assim, os jogos desempenham um papel de orientação de condutas a serem compartilhadas pelos alunos e professores; eles podem, ao mesmo tempo, intervir individual ou coletivamente no espaço da sala de aula e, quan- 
do executados estabelecem relações com a cognição e com a emoção dos jogadores. São capazes de promover a autonomia, a criatividade, o autocontrole sobre as emoções e os valores como a paciência e disciplina; são promotores da articulação de estratégias para os desafios impostos, assim bem como a criação de planejamentos de ações pensadas para decisões mais acertadas.

Desse modo, a relevância de se implantar jogos no processo pedagógico se faz importante e deve estar integrado ao currículo escolar conforme proposta da Lei de Diretrizes e Bases (LDB/96), para atender à parte diversificada do currículo. A relevância está em ser além de um eixo integrador, estendendo-se à ferramenta didática para a promoção do desenvolvimento pedagógico e social do aluno no espaço escolar.

Assim, a escolha dessa temática de pesquisa se justifica, pois, o xadrez, quando introduzido na sala de aula, como parte diversificada do currículo, se faz não só oportunidade de aprendizado acerca do jogo, mas também proposta de melhoria gradativa de habilidades de raciocínio e educação disciplinar. Além disso, sua prática pode ser considerada com proposta pluridisciplinar, haja vista a infinidade de oportunidades de ser integrado a demais disciplinas da grade curricular.

A metodologia de pesquisa proposta se caracteriza como mista, sendo ela: (1)

bibliográfica, pois apoia-se na consulta da literatura contemporânea para fundamentação e contextualização das contribuições do xadrez para o processo de ensino-aprendizagem e; (2) descritiva, pois visa gerar dados e informações, a partir de objetivo definido relacionado ao assunto - ou seja, relacionado aos seus aspectos pedagógicos e sociais a serem explorados no contexto educativo (GIL, 2008).

\section{A IMPORTÂNCIA DOS JOGOS NA EDUCAÇÃO}

Todas as crianças, em idade escolar, necessitam se agrupar para atividades diversas, onde os jogos se incluem. Os jogos, em fase escolar, se resumem em importantes instrumentos didáticos (GOULART; FREI, 2008).

Já na Antiguidade o jogo se presente na sociedade, onde era praticando tanto pelo adulto, quanto pela criança. Entretanto, era visto como uma atividade física. Com a evolução, aos dias de hoje, o jogo passou a ser visto como atividade intelectual e social, estendendo-se ao âmbito educativo (ALVES, 2001).

Os jogos de exercício, que se utilizam do corpo, são os primeiros jogos para as crianças. Aos poucos, passam para os jogos simbólicos, com as percepções e representações exteriores, por meio do uso da imaginação. Entretanto, já com 7 anos, as crianças chegam à idade dos jogos de regras, coincidindo assim com sua fase/idade de operações concretas. Nesse estágio, elas abandonam os jogos onde „ditavam as regras $^{\text {ee }}$ e passam a cumprir as regras dos jogos das quais participam. Chega-se à fase dos limites, da compreensão, da discussão e da inserção em grupo (ALVES, 2001).

Estar inserida em grupo compreende a criança estar inserida em sociedade. Considerando que toda sociedade tem regras e que para o cumprimento de regras faz-se necessário uma “educação". Para tanto, o jogo ganha uma carac- 
terística de ferramenta para o processo educativo de uma criança, podendo ser usado no contexto escolar (REIS, 2009).

Reis (2009) acredita que, quando a criança ingressa à escola, ela se vê diante de inúmeras regras a se sujeitar e sua adaptação em relação à nova rotina pode ser mais fácil se feita em um processo onde os jogos se fazem presentes. Deste modo, é um grande erro ignorar os jogos no âmbito educativo, principalmente por parte dos professores.
Alves (2001) ressalta a importância de saber diferenciar o significado dos jogos para adultos e crianças. Enquanto que, para um adulto, os jogos funcionam como lazer, para as crianças, os jogos fazem parte do universo educativo e formativo, dispostos e disponíveis por todos os lados e em quaisquer ocasiões.

\begin{tabular}{|c|c|}
\hline $\begin{array}{c}\text { Jean-Jacques } \\
\text { Rousseau } \\
(1712-1778)\end{array}$ & $\begin{array}{c}\text { Defendia uma educação através do contato com a natureza e propunha o uso de jogos, brin- } \\
\text { quedos, esportes, instrumentos variados, linguagem, música e Matemática (geometria), em } \\
\text { substituição a uma disciplina rígida e o uso excessivo da memória. }\end{array}$ \\
\hline $\begin{array}{c}\text { Friedrich Froebel } \\
(1782-1852)\end{array}$ & $\begin{array}{c}\text { Defendia o jogo como uma atividade de expressão da criatividade em que a criança toma } \\
\text { consciência do tempo e do espaço. }\end{array}$ \\
\hline $\begin{array}{c}\text { Édouard } \\
\text { Claparède } \\
(1873-1940)\end{array}$ & Acreditava no jogo como um modelo educativo. \\
\hline $\begin{array}{c}\text { John Dewey } \\
(1859-1952)\end{array}$ & $\begin{array}{c}\text { Defendia a aprendizagem como um processo ativo e o ensino baseado em experiências práti- } \\
\text { cas na sala de aula, criticava a educação tradicional, o intelectualismo e a memorização }\end{array}$ \\
\hline $\begin{array}{c}\text { Ovídio Decroly } \\
(1871-1932)\end{array}$ & $\begin{array}{c}\text { Autor da expressão ,jogos educativosé, defendia a permanente interação entre educação e } \\
\text { sociedade e que a escola deveria ser um prolongamento da vida. }\end{array}$ \\
\hline $\begin{array}{c}\text { Cousinet } \\
(1881-1973)\end{array}$ & $\begin{array}{c}\text { Foi um dos fundadores da Escola Nova, também compartilhava as ideias de Claparède e } \\
\text { defendia o jogo e a brincadeira como atividades naturais da criança considerando que a ação } \\
\text { educativa precisava fundamentar-se sobre elas (o jogo é a base do seu método pedagógico de } \\
\text { trabalho em grupo). }\end{array}$ \\
\hline $\begin{array}{c}\text { Jean Piaget } \\
(1896-1980)\end{array}$ & $\begin{array}{c}\text { Estudioso da importância do jogo como auxiliar do processo de desenvolvimento cognitivo e } \\
\text { social da criança. Na sua visão, os jogos têm dupla função: consolidar os esquemas formados } \\
\text { e dar prazer ou equilíbrio emocional à criança. }\end{array}$ \\
\hline
\end{tabular}

Quadro 1 - A importância e evolução dos jogos no processo educativo

Fonte: Organizado pelo autor, a partir de Melegari (2007, p. 16-17).

Melegari (2007) considera que o jogo auxilia, ainda, em tudo que se refere à descentralização, oportunizando que a criança saia do seu ponto de vista único e egocêntrico e passe a olhar qualquer situação de uma forma diferente, potencializando também a sua linguagem para argumentação, sua criatividade para promover soluções adversas e optar pela alternativa mais óbvia, a partir do raciocínio lógico potencializado pela situação.
Quando o aluno é desafiado a desenvolver o seu próprio instrumento (jogo) de aprendizagem, a expectativa é propiciá-lo a desenvolver o seu raciocínio no processo de elaboração, construção e assimilação do conhecimento. Assim, o jogo favorece 0 desenvolvimento físico, cognitivo, afetivo, social e moral do aluno (CURTY, 2011, p. 3).

Deste modo, sendo o jogo uma excelente ferramenta didática-pedagógica, deveria ter mais 
atenção por parte dos envolvidos na educação (professores e alunos), cabendo aos professores aterem-se para a valorização desta ferramenta enquanto facilitadora do processo de ensinoaprendizagem, onde segundo Angélico e Porfírio (2010), o xadrez se enquadra como uma excelente alternativa/opção de escolha para o trabalho cotidiano em sala de aula.

\section{O JOGO DE XADREZ}

O jogo de xadrez, tanto em sua criação, quanto em sua prática, data no século IV antes de Cristo, embora seu primeiro registro na Literatura tenha sido mil anos mais tarde (LASKER, 2009).

Para a compreensão de que o xadrez se enquadra como uma excelente alternativa/opção de escolha para o trabalho cotidiano no processo ensino-aprendizagem (ANGÉLICO; PORFÍRIO, 2010), é necessário recorrer sobre um questionamento básico de Becker (1978): mas como é exatamente o jogo de xadrez?

O jogo de xadrez é disputado em um tabuleiro de trinta e duas casas brancas e trinta e duas casas pretas. No início do jogo, cada enxadrista ou xadrezista, nomes que se dá ao praticante de xadrez, tem em seu controle dezesseis peças com diferentes formatos e características. Sendo elas: reis, rainhas, torres, bispos, cavalos e peões. O objetivo do jogo é dar xeque-mate ou mate no Rei adversário. Teóricos do enxadrismo desenvolveram uma grande variedade de estratégias e táticas para se atingir este objetivo, muito embora, na prática, ele não seja um fato muito comum, já que os jogadores em grande desvan- tagem ou iminência de derrota têm a opção de abandonar (desistir) a partida, antes de receberem o mate (CURTY, 2011, p. 1).

No jogo, cada uma de suas peças possui movimentos característicos (LIMA, 2002). Contudo, sempre que uma peça é movida para uma casa adversária, a peça que está na referida casa é capturada (BATISTA; BORGES, 2009). Deste modo, a peça que estará na jogada será movida para a casa do oponente, sendo então, a peça do oponente é retirada do tabuleiro (SHENK, 2007). As peças do jogo são: o Rei, a Dama, a Torre, o Bispo, o Cavalo e o Peão (FILGUTH, 2007). O REI move-se ou captura peças em qualquer sentido, uma casa de cada vez. Os reis nunca podem se tocar. O rei é a única peça que não pode ser capturada. A DAMA move-se ou captura em qualquer sentido, quantas casas quiserem desde que seu caminho não esteja obstruído por alguma peça da mesma cor. A TORRE move-se ou captura nas linhas e colunas (horizontal e vertical), seguindo num único sentido em cada lance. $\mathrm{O}$ BISPO move-se ou captura pelas diagonais, seguindo num único sentido em cada lance. Cada jogador tem dois bispos: um anda pelas casas pretas e outro pelas casas brancas. O CAVALO é o único que salta sobre as peças (pretas ou brancas). O movimento do cavalo assemelha-se à letra „L"e, formada por quatro casas.

O PEÃO move-se para a casa à sua frente, desde que não esteja ocupada. Ao ser movido pela primeira vez, cada peão pode andar uma ou duas casas. $O$ peão é a única peça que captura de maneira diferente do seu movimento. A captura é feita sempre em diagonal, uma casa apenas. O peão nunca se move nem captura para trás (ANGÉLICO; PORFÍRIO, 2010, p. 4-5). 
A Figura 1 exibe o tabuleiro do xadrez com a posição inicial das peças.

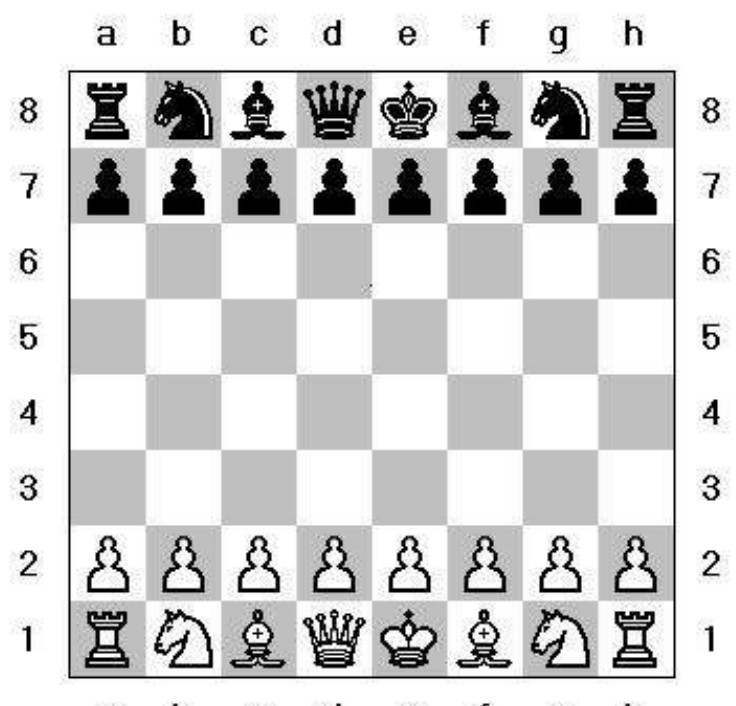

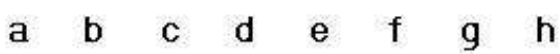

Figura 1 - Posição Inicial das Peças

Fonte: Angélico Porfírio (2010, p.5)

O objetivo do jogo se resume no ,xequemate $^{\text {ee }}$ ao Rei adversário. $\mathrm{O}$ xeque-mate acontece quando o Rei adversário se encontra em xeque, não existindo mais nenhum movimento a ser realizado para escapar. Além disso, os principais movimentos do jogo são: Roque, Promoção e En Passant.

Em sua filosofia, o xadrez não se resume em um jogo de azar - como muitos sujeitos, ainda não adeptos ao jogo pensam. Ele se resume em um jogo de regras e, dentro do senso comum, é conhecido e reconhecido pela extensão de uma partida e pela sua complexidade de jogadas. Ou seja, o xadrez resume-se em um jogo de regras, com jogadas dinâmicas, que demanda tempo para estruturação das jogadas adequadas de acordo com cada movimento e, principalmente que, o êxito de todos os movimentos (ou jogadas) está associado à inteligência humana (ANGÉLICO; PORFÍRIO, 2010), conforme elucida Maurício de Souza em uma tirinha de humor, conforme a Figura 2.

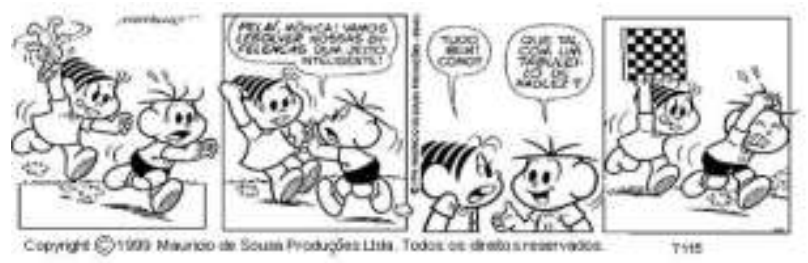

Figura 2 - Tirinha sobre o xadrez

Fonte: Angélico Porfírio (2010, p.5)

Segundo Filguth (2007), o xadrez tem muitas vantagens e, portanto, pode e deve ser inserido no processo educativo e no âmbito escolar e, sua prática no ensino deve ir além dos jogos de xadrez de competições - conforme mostrado, na sequência.

\section{CONTRIBUIÇÕES DO JOGO DE XADREZ NO PROCESSO DE ENSINO- APRENDIZAGEM}

De um modo geral, o jogo do xadrez constitui-se de estímulos e repostas para os problemas (situações) capazes de promover a capacidade e a habilidade cognitiva daqueles que jogam. Por tal característica, o jogo já faz parte de currículos escolares de alguns países (PLANETA XADREZ, 2011), tais como: União Soviética, Alemanha e Argentina. Recentemente, em Cuba e Venezuela. No Brasil, um projetopiloto foi introduzido em uma escola do Paraná nos anos 80 e o sucesso do mesmo, fez com que o Ministério de Educação e Cultura (MEC) começasse uma capacitação e habilitação de profissionais de demais estados (HAMZE, 2011). Na educação, especificamente no ambiente escolar, o uso do xadrez pode se dar mediante infinitas possibilidades e sua apresentação pode ocorrer enquanto tema transversal, enriquecendo e permeando a prática educativa, tanto em diversas áreas 
quanto em formato de disciplina para séries iniciais. Em 20 de dezembro de 1996, a Lei n. 9.394 estabeleceu as Diretrizes e Bases da Educação Nacional. Nesta, os artigos 26 e 27, tratam da inclusão do xadrez nas escolas, na parte diversificada dos currículos e também na parte consagrada à promoção do desporto (BRASIL, 1996). Para Curty (2011), sobre o jogo de xadrez, enquanto situação educativa, privilegiando social e cognitivamente os envolvidos no processo: [...] não pode ser imposto nem dele se exigir resultados; no entanto, é ordem e cria ordem, pois aponta para os limites a serem aceitos ou superados; pode diminuir resistências, pois rompe com a rigidez, com o autoritarismo, o controle e o mando, democratizando as relações; não se confunde com fetiches metodológicos, fórmulas mágicas ou modismo; exige uma postura consciente e uma abertura para o risco, a ambivalência e o incerto; ao mesmo tempo, pode tornar real o prazer da descoberta, o encantamento que seduz a entrega ao novo [...]. Promotor da aprendizagem e do desenvolvimento passa a ser considerado nas práticas escolares como importante aliado para o ensino, já que coloca o aluno diante de situações de jogo pode ser uma boa estratégia para aproximá-lo dos conteúdos culturais a serem veiculados na escola, além de poder estar promovendo o desenvolvimento de novas estruturas cognitivas (CURTY, 2011, p.3).

Para compreensão do jogo em âmbito escolar, as características do jogo podem ser confrontadas com as suas implicações nos aspectos educacionais, fundamentados pela formação do caráter (pela formação social), conforme ponderado pelo Quadro 2.
Quadro 2 - Característica do xadrez e suas implicações educativas

\begin{tabular}{|c|c|}
\hline Características do Xadrez & $\begin{array}{l}\text { Implicações nos aspec- } \\
\text { tos educacionais e de } \\
\text { formação do caráter }\end{array}$ \\
\hline $\begin{array}{l}\text { Fica-se concentrado e } \\
\text { imóvel na cadeira }\end{array}$ & $\begin{array}{l}\text { O desenvolvimento do } \\
\text { autocontrole psicofísico. }\end{array}$ \\
\hline $\begin{array}{l}\text { Fornece um número de } \\
\text { movimentos num determi- } \\
\text { nado tempo }\end{array}$ & $\begin{array}{c}\text { Avaliação da estrutura } \\
\text { do problema e do tempo } \\
\text { disponível }\end{array}$ \\
\hline $\begin{array}{l}\text { Movimento das peças } \\
\text { após exaustiva análise de } \\
\text { lances }\end{array}$ & $\begin{array}{l}\text { Desenvolvimento da } \\
\text { capacidade de pensar } \\
\text { com abrangência e pro- } \\
\text { fundidade }\end{array}$ \\
\hline $\begin{array}{l}\text { Após encontrar um lance, } \\
\text { procurar outro melhor. }\end{array}$ & $\begin{array}{l}\text { Tenacidade e empenho } \\
\text { no progresso contínuo }\end{array}$ \\
\hline $\begin{array}{l}\text { Partindo de uma posição a } \\
\text { princípio igual, direcionar } \\
\text { para uma conclusão bri- } \\
\text { lhante (combinação) }\end{array}$ & $\begin{array}{l}\text { Criatividade e imagina- } \\
\text { ção }\end{array}$ \\
\hline $\begin{array}{l}\text { O resultado indica quem } \\
\text { tinha o melhor plano }\end{array}$ & $\begin{array}{l}\text { Respeito à opinião do } \\
\text { interlocutor }\end{array}$ \\
\hline $\begin{array}{l}\text { Dentre as várias possibili- } \\
\text { dades, escolher uma úni- } \\
\text { ca, sem ajuda externa. }\end{array}$ & $\begin{array}{l}\text { Estímulo à tomada de } \\
\text { decisões com autonomia }\end{array}$ \\
\hline $\begin{array}{l}\text { Um movimento deve ser } \\
\text { consequência lógica do } \\
\text { anterior e deve apresentar } \\
\text { o seguinte }\end{array}$ & $\begin{array}{l}\text { Exercício do pensamento } \\
\text { lógico, auto consistência } \\
\text { e fluidez de raciocínio. }\end{array}$ \\
\hline
\end{tabular}

Fonte: Angélico e Porfírio (2010, p. 16)

De acordo com Angélico e Porfírio (2010), todos os elementos característicos do xadrez podem ser trabalhados durante o processo de ensino-aprendizagem com a prática do xadrez e, deste modo, podendo ser considerado como um recurso contributivo para a resolução dos desafios e conflitos cotidianos escolares.

Capablanca, um ex-campeão mundial de xadrez, escreveu que: "o Xadrez é algo mais do que um jogo; é uma diversão intelectual que tem um pouco de Arte e muito de Ciência. É, além 
disso, um meio de aproximação social e intelectual" (PLANETA XADREZ, 2011, p.1). Considerando que na citação o, intelectual ${ }^{e e}$ assume o sentido de „cognição ${ }^{\circ e}$ ou seja, de desenvolvimento - nas linhas que seguem os aspectos pedagógicos e sociais do xadrez, enquanto recursos para o processo ensino-aprendizagem são destacados.

\section{ASPECTOS PEDAGÓGICOS}

É na idade escolar que as crianças necessitam agrupar-se para a prática de atividades diversificadas, onde o jogo é uma das principais. Nessa fase, o jogo é considerado com um instrumento lúdico e didático, utilizado na educação para a promoção de ações pedagógicas (GOULART; FREI, 2008). E como qualquer outro jogo, o xadrez é dotado de valor pedagógico, sendo capaz de promover um processo educacional pautado na criticidade, na cooperação e na disciplina (TRINDADE, 2007). O ensino e a prática do xadrez têm relevante importância pedagógica, na medida em que tal procedimento implica, entre outros, no exercício da sociabilidade, do raciocínio analítico e sintético, da memória, da autoconfiança e da organização metódica e estratégica do estudo. O jogador de xadrez, constantemente exposto a situações em que precisa efetivamente olhar, avaliar e entender a realidade pode mais facilmente, aprender a planejar adequada e equilibradamente, a aceitar pontos de vista diversos, a discutir questionários e compreender limites e valores estabelecidos e a vivenciar a riqueza das experiências de flexibilidade e reversibilidade de pensamentos e posturas (PIMENTA, 2008, p.4).

Angélico e Porfírio (2010) acreditam que, por caracterizar-se como uma atividade promotora do desenvolvimento, pode facilitar a aprendizagem de outros conteúdos ou disciplinas, destacando como principais: Matemática, Artes, História, Educação Física, Geografia, Filosofia (Ética), dentre outros. O xadrez é considerado como um excelente suporte pedagógico visto que se relacionam com diversas disciplinas, tais como: Matemática; Artes; História; Geografia, além da Ética, etc. Na Matemática explora-se inicialmente o tabuleiro e a movimentação das peças associadas com a Geometria e suas dimensões. Nas Artes, exploram-se as formas das peças através do uso da argila, pintura, técnicas com materiais recicláveis. Na História, pode ser trabalhada a questão da origem do xadrez, a cultura dos seus povos e a relação entre aspectos sociais e políticos. Na Geografia, pode ser abordada a localização onde o jogo de xadrez era praticado.

E finalizando, quando se faz referência à Ética, seria quanto à importância das regras e o respeito que deve existir para com o parceiro de jogo (CRISTINE, 2015, p.1). Ainda, segundo Cristine (2015), pedagogicamente, se promovido por meio da interdisciplinaridade, é possível preparar os alunos para tomada de decisões que demandam o raciocínio lógico e rápido, além da contribuição para a integridade dos mesmos, enquanto cidadãos, de uma forma muito lúdica. Trabalhos em psicopedagogia demonstram que o xadrez é um precioso coadjuvante escolar, e até psicológico. Assim, pode-se utilizar inicialmente a motivação quase espontânea do aluno em relação ao xadrez visando a provocar ou facilitar 
a sua compreensão em outras disciplinas. Em uma segunda etapa, extrapola-se o universo artificial criado pelas regras do jogo como modelo de estudos de situações concretas. Isto pode aplicar-se a todos os campos do conhecimento - à história, à sociologia, ao direito e à literatura, entre outros - e sobre tudo à matemática e à pedagogia (CURTY, 2011, p.5).

$\mathrm{O}$ aluno (jogador) enquanto pratica o xadrez pode desenvolver um pensamento sistemático e organizado, considerando que as inúmeras possibilidades de movimentações (jogadas), assim bem como a seleção delas (escolhas) permite um preparo para o enfrentamento de situações (problemas) e, automaticamente, de decisões promovidas por meio de um raciocínio óbvio (PENTEADO, COQUEIRO, HERMANN, 2011).

[...] as jogadas dependem apenas de quem está jogando. Durante todo o jogo, a cada lance, o praticante deve pensar e tomar decisões. Fazendo isso, o praticante estará desenvolvendo suas capacidades superiores ou funções psicológicas superiores, das quais Vigostski (1998) aponta como exemplos: pensamento abstrato, raciocínio, atenção, memorização, capacidade de planejamento, entre outras. Sendo assim, a prática do jogo de xadrez, pode permitir o desenvolvimento simultâneo de capacidades como raciocínio lógico, da memória, da atenção, imaginação. Qualidades fundamentais para o desenvolvimento dos estudantes (PENTEADO, COQUEIRO, HERMANN, 2011, p. 2).

Mesmo diante dessas vantagens, o sucesso do jogo no processo educacional depende da mediação do professor, pois cabe a ele encai- xar o jogo em momentos oportunos (CURTY, 2011).

\section{ASPECTOS SOCIAIS}

"O jogo de xadrez é um eficiente meio para se formar um indivíduo social, com valores bem definidos e características importantes como pensamento crítico para conviver-se em sociedade" (CURTY, 2011, p. 7).

Segundo Hamze (2011) o jogo do xadrez é dotado de benefícios morais para as crianças, tais como: o respeito mútuo, a autonomia, a tolerância, o espírito de competição, o sentimento de vitória e de derrota, conhecer e reconhecer o ponto de vista do outro.

Outra qualidade importante adquirida também durante a seleção de jogadas é a autoconfiança na tomada de decisões [...]. No jogo de xadrez, apesar de ser praticado em dupla, cada enxadrista terá que tomar a decisão sobre a jogada individualmente, o que favorece a autoconfiança nas decisões (PENTEADO, COQUEIRO, HERMANN, 2011, p. 2).

Angélico e Porfirio (2010) publicaram resultados de pesquisas e investigações que comprovam que o jogo do xadrez permite o desenvolvimento da autoconfiança, da autoestima, da concentração e de empatia.

Para Trindade (2007), o valor social do xadrez para a promoção da educação de crianças e adultos está na promoção de oportunidades que desenvolvem o cooperativismo e os aspectos emocionais de todos os participantes.

Além disso, como o jogo de xadrez é um jogo longo, que exige pensamento elaborado ra- 
ciocínio lógico, para que as jogadas sejam certeiras exige-se de seus jogadores uma certa tranquilidade, sendo a mesma mais um dos benefícios dos aspectos sociais do jogo, considerando que treinam as crianças à pacificação, à tranquilidade, combatendo assim a realidade marcada pela indisciplina e pela agitação comportamental dentro das salas de aula (PENTEADO, COQUEIRO, HERMANN, 2011). Pimenta (2008) considera que o xadrez possa enriquecer os indivíduos culturalmente, haja vista que a sua prática (o seu exercício) requer práticas de sociabilidade, de autoconfiança desenvolvida, de compreensão da realidade e, acima de tudo, de equilíbrio para as tomadas de decisões, não só nas partidas do jogo, mas, principalmente, preparando o sujeito-aluno para qualquer situação-problema que o envolva, no processo de ensino-aprendizagem e em sua convivência em sociedade.

Para Angélico e Porfirio (2010), a utilização social do jogo do xadrez na escola se encaixa para a preparação da criança para o seu futuro, considerando que o jogo do xadrez confere um significado semelhante à vida: o tabuleiro é „o campo de batalha“e, a sociedade; as peças são „os exércitos"e ou os sujeitos inseridos na sociedade, que por meio de ,regras ${ }^{\text {ee }}$ ou leis se movimentam com estratégias para vencer ou com „proposta de soluçõese para resolução de seus problemas.

\section{CONCLUSÃO}

O jogo é fundamental para o desenvolvimento cognitivo de uma criança e, muitos estudiosos, durante o processo histórico, enaltece- ram a sua importância para o desenvolvimento saudável. Por meio de suas práticas, promove uma representação exterior e de interação social, organizando o pensamento ao mesmo tempo em que promove a formação do caráter. Os objetivos de pesquisa foram cumpridos, evidenciando que, especificamente, o jogo de xadrez, devida às suas características desportivas, promove o exercício do raciocino lógico, ajuda no aprimoramento da concentração, e da autoconfiança. Além disso, comprova-se que o mesmo tenha um valor social e pedagógico importante, assumindo-se como uma ferramenta para o processo de ensinoaprendizagem, se utilizado em ambiente escolar.

Todas as hipóteses de pesquisa foram confirmadas, onde concluiu-se que o xadrez é sinônimo de estímulo e motivação para o desenvolvimento da inteligência dos alunos, bem como para o reforço de regras e de disciplina entre eles, modifica a cultura na escola, desenvolve habilidades e garante conhecimentos a serem adquiridos no contexto escolar.

Registra-se que, toda a bibliografia consultada e utilizada esteve devidamente citada no entremeio do conteúdo e referenciada, com vistas ao cumprimento dos padrões de ética de pesquisa.

Em relação às limitações de pesquisa, a escassez de publicações específicas sobre o uso do xadrez para a promoção do ensinoaprendizagem na escola foi motivo de dificuldade para a estruturação do conteúdo. Entretanto, considerando a mesma escassez de publicações, acredita-se que a edificação deste artigo venha a contribuir para a comunidade acadêmica e científica que pesquisa sobre o tema. Além disso, contribui, ainda, para a autoria do mesmo, tanto 
(profissionalmente) como futuro pedagogo, quanto (pessoalmente) como apreciador do jogo de xadrez.

Para as sugestões de trabalhos futuros, pretende-se dar continuidade ao tema em pesquisa, contudo, aprofundando em suas contribuições específicas para cada uma das principais disciplinas curriculares, deste modo passando a reestruturar seu conteúdo, aperfeiçoando-o e enriquecendo-o enquanto contribuição acadêmica e científica.

\section{REFERÊNCIAS}

ALVES, Eva Siqueira. A Ludicidade e o Ensino de Matemática: Uma prática possível. Campinas: Papirus, 2001

ANGÉLICO, Lays Pedro; PORFÍRIO, Luciana Cristina. O jogo de xadrez modifica a escola: Por que se deve aprender xadrez e tê-lo como eixo integrador no currículo escolar? Diálogos Acadêmicos, v.1, n.1, jan. 2010 .

BATISTA, Gerson Peres; BORGES, Joel Cintra. Os mestres do xadrez. São Paulo Universo dos Livros, 2009.

BECKER, Idel. Manual de Xadrez. 7. ed. São Paulo:Nobel, 1978.

BRASIL. Ministério da Educação e Cultura. Lei de Diretrizes e Bases da Educação Nacional. Lei n. 9.394 de 20 de dezembro de 1996.

CRISTINE, Elen. O jogo de xadrez no processo de ensino - aprendizagem. Mundo Educaçãa, 2015. Disponível em: <https://goo.gl/vNm5jH >. Acesso em: 20 maio 2016.

CURTY, Maria Brandolfo. O Ensino-Aprendizagem da Matemática Através do Jogo de Xadrez. 2011. Disponível em: <http://www.impactosmt.com.br/index.php/artigos/21o-ensino-aprendizagem-da-matematica-atraves-dojogo-de-xadrez>. Acesso em: 15 nov. 2016.

FILGUTH, Rubens. A Importância do Xadrez. Porto Alegre: Artmed, 2007.
GIL, Antonio Carlos. Como elaborar projetos de pesquisa. 4. ed. São Paulo: Atlas, 2008.

GOULART, Edson; FREI, Fernando. O jogo de xadrez como ferramenta para o ensino da matemática às crianças do ensino fundamental.2008.In: ANGÉLICO, Lays Pedro; PORFÍRIO, Luciana Cristina. O jogo de xadrez modifica a escola: Por que se deve aprender xadrez e tê-lo como eixo integrador no currículo escolar? Diálogos Acadêmicos, v.1, n.1, jan. 2010.

HAMZE, Amelia. Jogo de xadrez nas escolas. 2011. Disponível em: $<$ http://educador.brasilescola.uol.com.br/trabalhodocente/xadrez.htm>. Acesso em: 20 out. 2016.

LASKER, Edward. História do xadrez. 5 ed. São Paulo: IBRASA, 2009.

LIMA, Darcy. Xadrez: aprenda a jogar. Rio de Janeiro: Universo dos Livro, 2002.

MELEGARI, Eliandra Moraes Pires Pedroso. O jogo de xadrez no ensino formal: estudo do projeto xadrez nas escolas. 2007. Disponível em: $<$ https://repositorio.ufsc.br/bitstream/handle/12345678 9/96546/Eliandra.pdf?sequence $=1>$. Acesso em: 26 out. 2016.

PENTEADO, Lucas; COQUEIRO, Valdete dos Santos; HERMANN, Wellington. O ensino de conteúdos matemáticos a partir do jogo de xadrez no Ensino Fundamental. VI Encontro de Produção Científica e Tecnológica, outubro, 2011.

PIMENTA, Ciro José C. Xadrez: esporte, história e sua influência na sociedade. 2008. Disponível em: <www.cdof.com.br/xadrez.htm>. Acessado em: 20 maio 2016.

REIS, Marlene Barbosa de Freitas. Interdisciplinaridade na Prática Pedagógica. Um desafio Possível. Revista de Educação, Linguagem e Literatura da UEG, v. 1, n. 2, out. 2009, p. 26-45.

TEIXEIRA, Carlos Alexandre Pereira; TEIXEIRA, Isianne Cristina Porto de Oliveira. O xadrez na educação básica: desenvolvendo metodologia de ensinoaprendizagem na Escola Municipal Colônia Agrícola. V Congresso Nordeste de Ciências do Esporte. Bahia, setembro, 2014.

TRINDADE, José J. Uma proposta didática para a utilização do jogo de xadrez no ensino de ciências. 2007. In: ANGÉLICO, Lays Pedro; PORFÍRIO, Luciana Cristina. O jogo de xadrez modifica a escola: Por que se deve aprender xadrez e tê-lo como eixo integrador no currículo escolar? Diálogos Acadêmicos, v.1, n.1, jan. 2010 . 
SHENK, David. O jogo imortal: o que o xadrez nos revela sobre a guerra, a arte, a ciência e o cérebro humano/David Shenk. Rio de Janeiro: Zahar, 2007.

Carlos Roberto Rodrigues

Acadêmico do Curso de Pedagogia da Universidade

Vale do Rio Verde (UninCor).

Luiza Procópio Sarrapio

Mestre em Educação. Docente do Curso de

Pedagogia da Universidade Vale do Rio Verde (UninCor). 